$$
\text { Special Reports from the Netherlands }
$$

\title{
EUTHANASIA, PHYSICIAN-ASSISTED SUICIDE, AND OTHER MEDICAL PRACTICES INVOLVING THE END OF LIFE IN THE NETHERLANDS, 1990-1995
}

\author{
Paul J. van der Maas, M.D., Ph.D., Gerrit van der Wal, M.D., Ph.D., Ilinka Haverkate, M.Sc., \\ Carmen L.M. de Graaff, M.A., John G.C. Kester, M.A., Bregje D. Onwuteaka-Philipsen, M.Sc., \\ Agnes van der Heide, M.D., Ph.D., Jacoueline M. Bosma, M.D., LL.M., and Dick L. Willems, M.D., Ph.D.
}

\begin{abstract}
Background In 1991 a new procedure for reporting physician-assisted deaths was introduced in the Netherlands that led to a tripling in the number of reported cases. In 1995, as part of an evaluation of this procedure, a nationwide study of euthanasia and other medical practices concerning the end of life was begun that was identical to a study conducted in 1990 .
\end{abstract}

Methods We conducted two studies, the first involving interviews with 405 physicians (general practitioners, nursing home physicians, and clinical specialists) and the second involving questionnaires mailed to the physicians attending 6060 deaths that were identified from death certificates. The response rates were 89 percent and 77 percent, respectively.

Results Among the deaths studied, 2.3 percent of those in the interview study and 2.4 percent of those in the death-certificate study were estimated to have resulted from euthanasia, and 0.4 percent and 0.2 percent, respectively, resulted from physician-assisted suicide. In 0.7 percent of cases, life was ended without the explicit, concurrent request of the patient. Pain and symptoms were alleviated with doses of opioids that may have shortened life in 14.7 to 19.1 percent of cases, and decisions to withhold or withdraw life-prolonging treatment were made in 20.2 percent. Euthanasia seems to have increased in incidence since 1990, and the ending of life without the patient's explicit request seems to have decreased slightly. For each type of medical decision except those in which life-prolonging treatment was withheld or withdrawn, cancer was the most frequently reported diagnosis.

Conclusions Since the notification procedure was introduced, end-of-life decision making in the Netherlands has changed only slightly, in an anticipated direction. Close monitoring of such decisions is possible, and we found no signs of an unacceptable increase in the number of decisions or of less careful decision making. (N Engl J Med 1996;335:1699-705.) (c)1996, Massachusetts Medical Society.
I $\mathrm{N}$ the Netherlands, euthanasia and physicianassisted suicide have been practiced with increasing openness, although technically they remain illegal. In 1990-1991 a nationwide study of euthanasia and other medical practices related to the ending of life was conducted, commissioned by a governmental committee chaired by Professor Jan Remmelink, the attorney general of the Dutch Supreme Court. ${ }^{1,2}$ The study attracted a great deal of attention, partly because it gave the first complete overview of medical decisions concerning the end of life in a single country.

At about the same time, a new procedure for reporting cases of euthanasia and physician-assisted suicide was introduced. ${ }^{3,4}$ Probably as a result, the number of reported cases of euthanasia increased, from 486 in 1990 to 1466 in 1995. In 1995-1996 we conducted a second nationwide study, almost identical to the first, in an evaluation of the new procedure that was commissioned by the ministers of health and justice. The purpose of the 1995 study was to make reliable estimates of the incidence of euthanasia and other medical practices pertaining to the end of life; to describe the patients, physicians, and circumstances involved; and to evaluate changes in these practices between 1990 and 1995. We conducted two separate studies, one based on interviews with a stratified sample of 405 physicians and the other based on responses to mailed questionnaires about a sample of 6060 deaths.

\section{METHODS}

\section{The Interview Study}

We interviewed a stratified random sample of 405 physicians that included 124 general practitioners, 74 nursing home physicians, and 207 physicians in five specialties (cardiology, surgery, internal medicine, pulmonology, and neurology). Such physicians attend 87 percent of all deaths in the Netherlands occurring in hospitals (where about 40 percent of deaths occur) and almost all

From the Department of Public Health, Erasmus University Rotterdam, Rotterdam (P.J.M., A.H.), the Institute for Research in Extramural Medicine, Vrije Universiteit Amsterdam, Amsterdam (G.W., I.H., B.D.O.-P., J.M.B., D.L.W.); and Statistics Netherlands, Voorburg (C.L.M.G. J.G.C.K.) - all in the Netherlands. Address reprint requests to Dr. van der Maas at the Department of Public Health, Erasmus University Rotterdam, P.O. Box 1738, 3000 DR Rotterdam, the Netherlands. 
deaths outside the hospital. To be selected for the study, the physicians interviewed had to have been practicing in their registered specialties since January 1, 1994, and to have worked at the same institution since then. So that the desired number of 410 interviews could be conducted, 559 physicians were sampled. Eightythree did not meet the criteria for selection, and 21 others had chronic illnesses or could not be located. Fifty physicians (11 percent of those who met the selection criteria) declined to take part in the study.

The interviews were conducted from November 1995 through February 1996 by about 30 experienced physicians. All the interviewers were trained intensively for the study. The questionnaire used to guide the interview ran to about 120 pages, and the interviews lasted $2^{1 / 2} 2$ hours on average.

To extrapolate our findings to all deaths in the Netherlands, we calculated weights based on the proportions of physicians of the various types who were represented in the sample. Our estimates of incidence were corrected for the 13 percent of in-hospital deaths that were attended by clinicians in specialties other than the five sampled, on the assumption that among these remaining deaths the various types of medical decisions related to the end of life were as frequent as in the deaths studied.

\section{The Death-Certificate Study}

The causes of death for all inhabitants of the Netherlands are reported to Statistics Netherlands. Patients are not mentioned by name on the cause-of-death forms, but the names of the reporting physicians are given. The medical officer in charge of the cause-of-death statistics selected a stratified sample containing the deaths occurring from August 1 through December 1, 1995. The forms for all 43,000 deaths in this period were examined by two physicians and assigned to one of five strata, denoted 0 through 4 . When the cause of death was one in which it was clear that no medical decision about the end of life could have been made (for example, a car accident resulting in an instant death), the death was assigned to stratum 0 . These cases were retained in the sample, but no questionnaires were sent to the physicians, because no further information was needed in order to determine that no medical decisions about the end of life had been involved. When the likelihood was deemed high that there had been a medical decision that may have hastened death, the death was assigned to stratum 4 .

The final sample contained half the cases in stratum 4,25 percent of the cases in stratum $3,12.5$ percent of those in stratum 2 , and 8.3 percent of those in strata 1 and 0 each. A procedure was devised to ensure that the physicians and the deceased persons would remain completely anonymous. All Dutch physicians received a letter explaining the purpose of the study and how anonymity would be guaranteed. Of the 6060 questionnaires mailed, 77 percent were returned. Nearly all were completed carefully, and many contained information in addition to that requested.

The study questionnaire contained 24 items. In classifying the responses in terms of the types of end-of-life medical decisions made, we studied how the respondents answered four questions. What did the physician do (or not do)? What was his or her intention in doing so? Was the physician's decision made at the request of the patient or after discussion with the patient? And was the patient competent (that is, able to assess the situation and make a decision about it adequately)?

Euthanasia was defined as the administration of drugs with the explicit intention of ending the patient's life, at the patient's explicit request. Physician-assisted suicide was defined as the prescription or supplying of drugs with the explicit intention of enabling the patient to end his or her own life (the administration of lethal drugs by both the patient and the physician was considered to be euthanasia). The ending of life without an explicit request was defined as the administration of drugs with the explicit intention of ending the patient's life without a concurrent, explicit request by the patient. The alleviation of pain and symptoms with opioids was defined as the administration of doses large enough that there was a probable life-shortening effect. A decision not to treat was defined as the withholding or withdrawal of potentially life-prolonging treatment.

In both studies the questionnaires used were almost identical to those used in the 1990 study. The study designs were identical, although the prospective part of the earlier study was not repeated. In the mailed questionnaires we avoided the terms euthanasia and physician-assisted suicide, because their connotations are too varied. Instead, we used wording that more closely described actual medical practice, permitting us to classify the answers in the categories defined here. In the interviews, terms such as euthanasia and physician-assisted suicide were used, since the interviewer would be able to discuss meanings and obtain more detailed information about the cases described. Thus, the two studies were designed to generate complementary information, with the interviews producing more detailed background information and the death-certificate study providing a strong quantitative framework. Ninety-five percent confidence intervals were calculated that took into account the stratification procedure and the probability of the various types of decisions in each stratum. ${ }^{5}$

\section{RESULTS}

\section{Incidence Estimates}

The two studies yielded similar estimates of incidence with regard to most of the practices studied (Table 1). There were 34,500 requests for euthanasia at a later time in the course of disease, a 37 percent increase from the 1990 number. There were 9700 explicit requests for euthanasia or physicianassisted suicide at a particular time, a 9 percent increase from 1990. In the interview study 2.3 percent of all deaths resulted from euthanasia, as compared with 2.4 percent in the death-certificate study. In 1990 the rates were 1.9 and 1.7 percent, respectively. Assisted suicide occurred in 0.4 percent of deaths in the interview study and 0.2 percent of deaths in the death-certificate study, as compared with 0.3 and 0.2 percent, respectively, in 1990. In both 1995 studies 0.7 percent of deaths involved ending the patient's life without the patient's explicit, concurrent request. In 1990, 0.8 percent of deaths in the death-certificate study occurred in this way.

The estimated incidence of the alleviation of pain and symptoms with a possible shortening of life differed in the two 1995 studies, probably because in the interviews the question was phrased somewhat more strictly. The death-certificate study offered the best basis for comparison with the earlier study, and it showed no significant change since then. Decisions to forgo treatment occurred in 20.2 percent of cases, as compared with 17.9 percent in 1990 . Thus, for more than 42 percent of all deaths in the Netherlands, medical decisions concerning the end of life seem to have been made. In about 2.0 percent of all deaths - the same figure that was reported in 1990 - the physicians' intentions were either ambiguous or inconsistent with their practices: in 1.4 percent of cases, the respondents said that they had alleviated pain and symptoms with opioids, but with the explicit intention of ending the patient's life; and in 
Table 1. Estimated Incidence of Medical Decisions Related to the End of Life.*

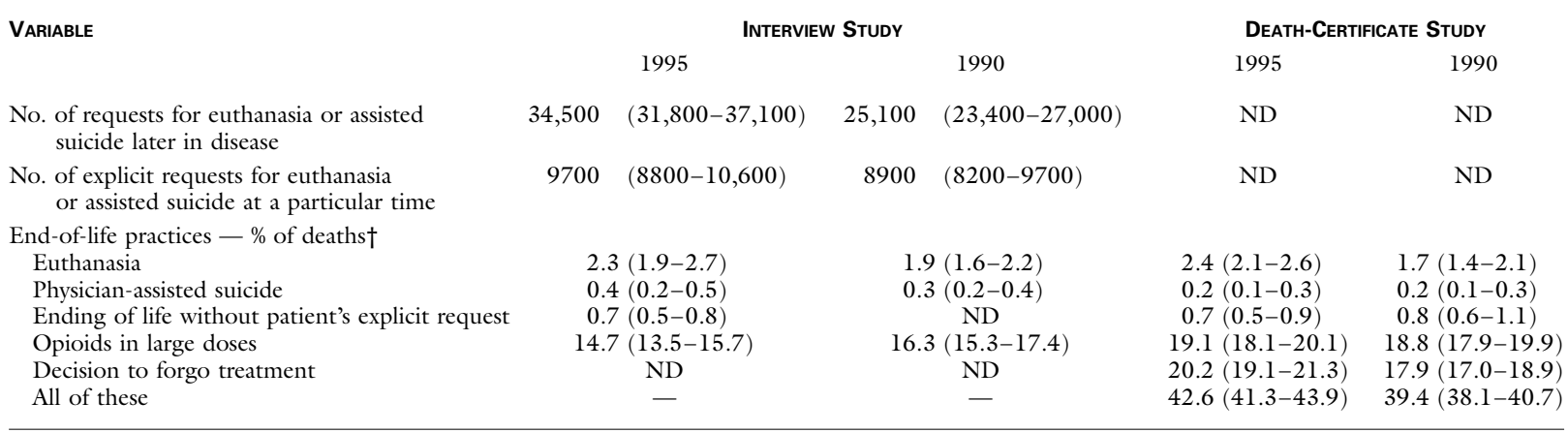

* Numbers in parentheses are 95 percent confidence intervals. ND denotes not determined, because the study data did not permit these estimates to be calculated.

†Percentages are based on the total number of deaths in the Netherlands: 135,546 in 1995 and 128,786 in 1990.

0.6 percent, they said that they had ended the patient's life without the patient's explicit request but had only partly intended to do so.

\section{Euthanasia and Physician-Assisted Suicide}

Of the physicians interviewed, 88 percent said they had received at least one request for euthanasia or physician-assisted suicide at a later time in the course of disease, whereas 77 percent had received at least one explicit request for a particular time. When asked if they had ever performed euthanasia or assisted in suicide, 53 percent confirmed that they had done so at some time, and 29 percent confirmed that they had done so in the preceding 24 months (Table 2). There were large differences among the three types of physicians. Among those who said they had never performed euthanasia or assisted in suicide, 35 percent said they could conceive of situations in which they would be prepared to do so. Among the remaining 12 percent, who could not conceive of such a situation, the majority said that they would be prepared to refer patients to a colleague if they requested euthanasia or assistance in suicide. These proportions are almost identical to those in the 1990 study.

Table 3 contains data obtained in the death-certificate study on the age, sex, and cause of death of the deceased persons and the type of physician involved. The percentage of all deaths in each category in which an end-of-life decision was made is shown. For instance, such a decision was made in 32 percent of all deaths of persons under the age of 50 . These percentages do not differ greatly according to age or sex, but they do differ according to the cause of death: in 61 percent of all deaths from cancer, medical decisions about ending the patient's life were made, as compared with 20 percent of all deaths from cardiovascular disease. Patients who received euthanasia or assistance in suicide tended to be young. Euthanasia was more common among female patients than among male patients, a finding not consistent with the findings in the interview study and the 1990 study. This was one of the rare instances in which the results of the interview study and those of the death-certificate study differed. Euthanasia and assisted suicide predominantly involved patients with cancer (79 percent). In most cases a general practitioner was involved. (In the Netherlands, somewhat over 40 percent of all deaths occur at home.)

\section{Ending Life without the Explicit Request of the Patient}

Among the physicians interviewed, 23 percent said that at some time they had ended a patient's life without his or her explicit request, and 32 percent said that they had never done so but that they could conceive of a situation in which they would, whereas 45 percent said that they had never done so and could not conceive of any situation in which they would. The corresponding figures in the 1990 study were 27 percent, 32 percent, and 41 percent, respectively.

The patients whose lives were ended without their explicit request also tended to be relatively young, and cancer was the predominant diagnosis (in the interview study, 60 percent of all cases involved cancer). In 57 percent of all cases, clinical specialists were involved. Table 4 shows some of the characteristics of the decisions made in these cases in the death-certificate study, the drugs administered, and the estimated interval by which the patient's life was shortened. In about half of all the cases, either the decision was discussed with the patient earlier in the illness or the patient had expressed a wish for euthanasia if suffering became unbearable. In the other cases the patient was incompetent. In 95 percent of 
Table 2. Physicians' Statements in the 1995 Interview Study about Their Practices and Attitudes with Regard to Euthanasia and Assisted Suicide.*

\begin{tabular}{|c|c|c|c|c|c|}
\hline \multirow[t]{2}{*}{ Stated Practice or Attitude } & \multirow[t]{2}{*}{$\begin{array}{l}\text { General } \\
\text { Practitioners } \\
(\mathbf{N}=\mathbf{1 2 4})\end{array}$} & \multirow[t]{3}{*}{$\begin{array}{l}\text { Clinical Specialists } \\
(\mathbf{N}=\mathbf{2 0 7})\end{array}$} & \multirow[t]{2}{*}{$\begin{array}{c}\text { Nursing Home } \\
\text { Physicians }(N=74)\end{array}$} & \multicolumn{2}{|c|}{ All Physicians } \\
\hline & & & & $\begin{array}{c}1995 \\
(\mathrm{~N}=405)\end{array}$ & $\begin{array}{c}1990 \\
(\mathrm{~N}=405)\end{array}$ \\
\hline & & & percent & & \\
\hline \multicolumn{6}{|l|}{$\begin{array}{l}\text { Performed euthanasia or } \\
\text { assisted suicide }\end{array}$} \\
\hline Ever & 63 & 37 & 21 & 53 & 54 \\
\hline During the previous $24 \mathrm{mo}$ & 38 & 16 & 3 & 29 & 24 \\
\hline $\begin{array}{l}\text { Never performed it but } \\
\text { would be willing to do so } \\
\text { under certain conditions }\end{array}$ & 28 & 43 & 64 & 35 & 34 \\
\hline $\begin{array}{l}\text { Would never perform it but } \\
\text { would refer patient } \\
\text { seeking it to another } \\
\text { physician }\end{array}$ & 7 & 15 & 10 & 9 & 8 \\
\hline $\begin{array}{l}\text { Would never perform it or } \\
\text { refer patient }\end{array}$ & 2 & 4 & 5 & 3 & 4 \\
\hline
\end{tabular}

cases, the decision was discussed with colleagues, nursing staff, or relatives (or usually some combination of the three). In 64 percent of all cases in which life had been ended without the patient's explicit request, morphine was the only drug administered, whereas in 18 percent neuromuscular relaxants were used in various combinations. In 33 percent of cases life was shortened by 24 hours at most, and in a further 58 percent it was shortened by at most one week. In the interview study the proportions were similar to those in the death-certificate study.

Further scrutiny of the case histories in the interview study showed that decisions to end life without the patient's request covered a wide range of situations, with a large group of patients having only a few hours or days to live, whereas a small number had a longer life expectancy but were evidently suffering greatly, with verbal contact no longer possible. The characteristics in Table 4 suggest that most of the cases in which life was ended without the patient's explicit request were more similar to cases involving the use of large doses of opioids than to cases of euthanasia. As compared with 1990, there was a small decrease in the proportion of these cases.

\section{Alleviation of Pain and Other Symptoms with Possible Life-Shortening Effects}

Eighty-four percent of all respondents had at some time sought to alleviate a patient's pain and other symptoms by administering opioids in such doses that the patient's life might have been shortened (in 1990, 82 percent reported doing so). In 85 percent of all such cases in the death-certificate study, the physician said that he or she had no intention of hastening death, but had taken into account the probability or certainty that death would occur, whereas in the other 15 percent of cases the physician at least partly intended to hasten the patient's death. The age and sex distribution of the patients in these cases was similar to that of all persons dying in the Netherlands, but more than half the cases involved cancer. Decisions of this type are relatively frequent in nursing homes, where about 16 percent of all deaths in the Netherlands occur. In 64 percent of cases the physician estimated that the patient's life had been shortened by less than 24 hours, and in 16 percent it was shortened by less than one week ( $\mathrm{Ta}-$ ble 4 ). In 43 percent of cases the decision to administer large doses of opioids was discussed with the patient and either an explicit request was made or, if the patient was incompetent, there was knowledge of a previous wish. In 86 percent of cases in which opioids were administered and there was no information about the patient's wishes, the patient was incompetent.

\section{Decision to Forgo Treatment}

Among the decisions to withhold or withdraw life-prolonging treatment, 66 percent were made with the intention of hastening death (or rather, of not prolonging life); in making the remaining decisions, the physician took into account the probability or the certainty that death would be hastened. In 10 percent of cases the decision involved artificial respiration; in 23 percent, tube feeding or artificial hydration; and in 2 percent, dialysis. The forgoing 
Table 3. Demographic and Mortality Variables and Data on the Responding Physician's Type of Practice, According to the Use of End-of-Life Medical Decisions, in the Death-Certificate Study.

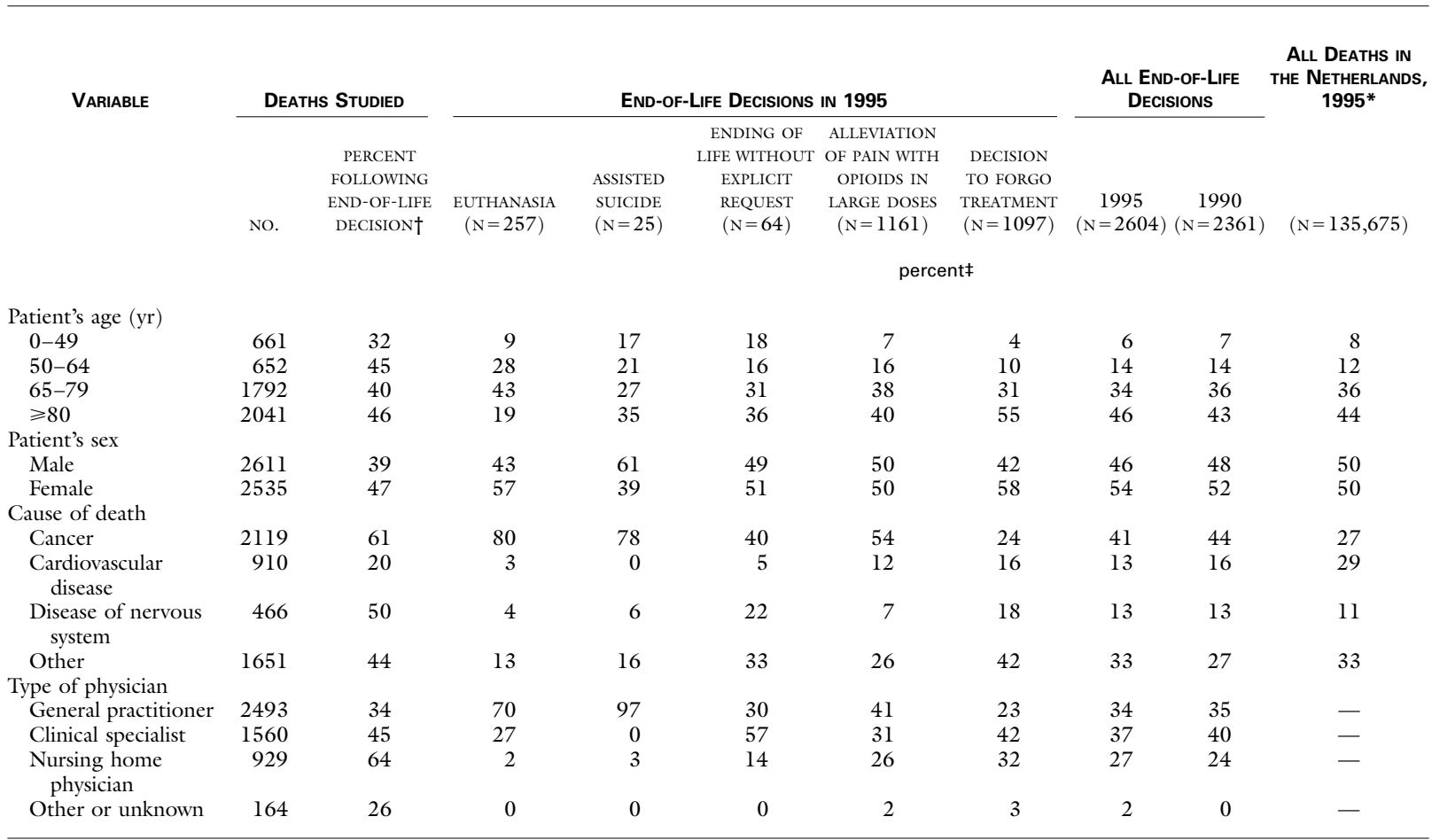

*Provisional figures for 1995 are shown.

$\dagger$ Percentages shown in this column are percentages of the number of cases studied.

$\ddagger$ Percentages shown in these columns are percentages of the group. Because of rounding, percentages for each variable do not all total 100 .

of other treatments (such as medication, surgery, or admission to the hospital for diagnostic purposes) generally affected survival less directly. The amount of time by which life was shortened was less than 24 hours in 42 percent of cases, less than one week in 28 percent, and over one month in 8 percent. Decisions to forgo treatment differed from the other practices studied. The patients tended to be older and were more often female, and the distribution of the diseases involved more or less followed the pattern of the causes of all deaths in the Netherlands (Table 3). Decisions to forgo treatment were made relatively often by nursing home physicians.

\section{DISCUSSION}

We believe this study presents a reliable overview of medical decisions about the end of life in the Netherlands, one that includes developments since 1990. In almost all relevant respects, the interviews and the mailed questionnaires yielded similar results. Participation rates were high. Only 11 percent of physicians declined to be interviewed, mainly for lack of time, and in the death-certificate study the response rate was 77 percent. All physicians in the Netherlands received a letter signed by the president of the Royal Dutch Medical Association and the Chief Inspector for Health Care, explaining the importance of the study and urging them to cooperate if they were invited to participate. The data collected could not be used in legal prosecution.

In the reports of the 1990 study, we foresaw an increased incidence of euthanasia and the other practices examined, for several reasons - increased mortality rates as a consequence of the aging of the population, an increase in the proportion of deaths from cancer as a consequence of a decrease in deaths from ischemic heart disease, the increasing availability of life-prolonging techniques, and possibly, generational and cultural changes in patients' attitudes. At the same time, we thought it likely that the incidence of decisions to end life without an explicit request by the patient would decrease, because of the growing openness with which end-of-life decisions are discussed with patients. ${ }^{1,2,6}$

A coherent picture emerges from the present study that confirms these expectations. Between 1990 and 1995 there were 37 percent more requests for physician-assisted death at a later time in the course of a patient's disease and 9 percent more explicit requests at a particular time, whereas the total number 
Table 4. Characteristics of Various Types of Medical Decisions Related to the End of Life in the Death-Certificate Study.

\begin{tabular}{|c|c|c|c|c|c|}
\hline Characteristic & $\begin{array}{l}\text { EUtHANASIA AND } \\
\text { AsSISTED SUICIDE } \\
(\mathbf{N}=\mathbf{2 8 2})\end{array}$ & $\begin{array}{l}\text { ENDING OF } \\
\text { LIFE WITHOUT } \\
\text { EXPLICIT } \\
\text { REQUEST } \\
(\mathbf{N}=\mathbf{6 4})\end{array}$ & $\begin{array}{l}\text { ALLEVIATION OF PAIN } \\
\text { WITH OpIOIDS IN } \\
\text { LARGE Doses } \\
\text { (N=1161) }\end{array}$ & $\begin{array}{c}\text { DeCISION to } \\
\text { Forgo TrEATMENT } \\
(\mathbf{N}=\mathbf{1 0 9 7})\end{array}$ & $\begin{array}{c}\text { ENDING OF } \\
\text { LIFE WITHOUT } \\
\text { EXPLICIT REQUEST, } \\
1990 \text { StUDY } \\
(\mathbf{N}=45)\end{array}$ \\
\hline & & & percent & & \\
\hline \multicolumn{6}{|l|}{ Previous discussion of the practice } \\
\hline Discussed, explicit request made by patient & 100 & - & 19 & 20 & - \\
\hline No explicit request, but discussed or wish stated & - & 52 & 24 & 25 & 60 \\
\hline Not discussed, no previous wish & - & 48 & 42 & 51 & 40 \\
\hline Unknown & - & - & 15 & 5 & - \\
\hline \multicolumn{6}{|l|}{ Competence } \\
\hline Yes & 97 & 21 & 37 & 26 & 37 \\
\hline No & 3 & 79 & 47 & 67 & 54 \\
\hline Unknown & 0 & 0 & 17 & 7 & 9 \\
\hline \multicolumn{6}{|l|}{ Decision discussed with others* } \\
\hline Colleagues & 83 & 59 & 31 & 52 & 69 \\
\hline Nursing staff & 33 & 65 & 30 & 47 & 64 \\
\hline Relatives or others & 70 & 70 & 50 & 68 & 84 \\
\hline No one & 4 & 5 & 16 & 5 & 2 \\
\hline Unknown & 2 & 0 & 19 & 7 & 2 \\
\hline \multicolumn{6}{|l|}{ Drugs administered } \\
\hline Morphine only & 25 & 64 & 73 & - & $44 \dagger$ \\
\hline $\begin{array}{l}\text { Morphine and other drugs (but not neuromuscular } \\
\text { relaxants) }\end{array}$ & 14 & 17 & 11 & - & $18 \dagger$ \\
\hline Neuromuscular relaxants (any combination) & 46 & 18 & 0 & - & $19 \dagger$ \\
\hline Other & 12 & 0 & 2 & - & $19+$ \\
\hline Unknown & 2 & 0 & 15 & - & $0 \dagger$ \\
\hline \multicolumn{6}{|l|}{ Amount of time by which life was shortened } \\
\hline$<24 \mathrm{hr}$ & 17 & 33 & 64 & 42 & 39 \\
\hline 1 day to $1 \mathrm{wk}$ & 42 & 58 & 16 & 28 & 46 \\
\hline$>\mathrm{l}$ wk to $1 \mathrm{mo}$ & 32 & 3 & 3 & 15 & 6 \\
\hline$>1 \mathrm{mo}$ & 9 & 6 & 1 & 8 & 8 \\
\hline Unknown & 0 & 0 & 15 & 7 & 0 \\
\hline
\end{tabular}

* More than one answer is possible.

†Data are from the 1990 interview study; these questions were not asked in the 1990 death-certificate study.

of deaths increased by somewhat over 5 percent. The incidence of euthanasia increased from 1.7 percent to 2.4 percent in the death-certificate study, and from 1.9 percent to 2.3 percent in the interview study. Although variability due to sampling cannot be ruled out as an explanation, the fact that in both substudies almost identical increases were found makes an artifact very unlikely. It may be surprising that the rate of physician-assisted suicide remained constant and low, given the general tendency toward patient autonomy. It must be kept in mind, however, that in the Netherlands the physician's responsibility in physician-assisted suicide is considered to be no different from that in euthanasia.

The frequency of cases in which life was ended without an explicit request by the patient has decreased somewhat since 1990. Here too, chance fluctuation cannot be ruled out as an explanation, but the decrease was found in both studies (the 1990 interview study did not permit sufficiently reliable estimates of this variable, but the number of cases then was certainly higher than in the 1995 study). The proportion of deaths in which opioids were ad- ministered with possible life-shortening effects remained constant from 1990 to 1995 , and the proportion in which life-prolonging treatment was withheld or withdrawn increased somewhat. However, there was a shift in intentions. The proportion of cases in which opioids were administered partly to hasten death dropped from 20 percent to 15 percent. It is very likely that a number of cases counted in this category in 1990 would now be considered cases of euthanasia. In the cases in which life-prolonging treatment was forgone there was also a shift toward a more explicit intention to hasten death.

Data from other countries on physicians' opinions about euthanasia and physician-assisted suicide and their actual use of these procedures are scarce. In a sample of U.S. oncologists, Emanuel et al. found that 57 percent had received a request for euthanasia or assisted death at some time, and that 14 percent had actually engaged in those practices. ${ }^{7}$ In a sample of general practitioners and hospital consultants in the United Kingdom studied by Ward and Tate, these proportions were 45 percent and 14 percent, respectively. ${ }^{8}$ Among physicians in South Australia 
studied by Stevens and Hassan, the proportions were 33 percent and 19 percent, ${ }^{9}$ and among Danish physicians studied by Folker et al. they were 30 percent and 5 percent. ${ }^{10}$ Lee et al. found that 21 percent of Oregon physicians had received a request for physician-assisted suicide in the past year and that 7 percent had written at least one lethal prescription at a patient's request. ${ }^{11}$ In Washington State 12 percent of physicians had received requests for physicianassisted suicide and 4 percent had received a request for euthanasia during the preceding year. ${ }^{12}$ In both cases 24 percent of requests were granted. Although the comparability of the studies is limited, these figures are consistently lower than those we found.

\section{Safe Ground or Slippery Slope?}

A major issue in the debate about euthanasia is whether some form of acceptance of euthanasia or assisted suicide when it is explicitly requested by a greatly suffering, terminally ill, competent patient is the first step on a slippery slope that will lead to an unintended and undesirable increase in the number of cases of less careful end-of-life decision making and to the gradual social acceptance of euthanasia performed for morally unacceptable reasons. Obviously, our data provide no conclusive evidence in either direction. Five years may be too short a period in which to observe important cultural changes, and our results may be valid only in the context of Dutch culture and the Dutch health care system, in which virtually all of the population is insured for health care costs and economic motives have not yet entered the realm of end-of-life decision making. Nevertheless, in our view, these data do not support the idea that physicians in the Netherlands are moving down a slippery slope.

As in 1990, a large majority of Dutch physicians consider euthanasia an exceptional but accepted part of medical practice. ${ }^{13}$ The number of requests for it has increased, but most of the requests are not granted. Physician-assisted death nowadays does not involve patients whose illnesses are less severe, as can be seen from our estimates of the amount of time by which life was shortened. Finally, there are no signs that the decision making has become less careful. Indeed, the increased frequency of consultation and better documentation of cases can be considered to indicate better decision making., ${ }^{4,14}$ The large majority of Dutch physicians are prepared to invest substantial time in participating in studies of this type and to make information on this difficult area of their practices public. As a result, further developments in end-of-life decision making can be monitored closely.

Supported in part by a grant from the Ministry of Health, Welfare, and Sports and the Dutch Ministry of Justice.

We are indebted to Johannes J.M. van Delden, M.D., Ph.D., Jo banna H. Groenewoud, M.D., and Piet J. Kostense, Ph.D., for their contributions to the study and to the manuscript; to Magda M. Henke-Kulakowska, M.D., Martien T. Muller, Ph.D., Henk Noort, M.A., and Marjolein D. Smit, M.D., for their contributions to the study; to Loes Pijnenborg, M.D., Ph.D., for her contribution to the manuscript; to the members of the Steering Committee for their continuous support throughout the study; to the thousands of physicians and public prosecutors who provided the study data; to the interviewers; and to the Royal Dutch Medical Association and the Chief Inspector for Health Care for their support of the study.

\section{REFERENCES}

1. van der Maas PJ, van Delden JJM, Pijnenborg L, Looman CWN. Euthanasia and other medical decisions concerning the end of life. Lancet 1991;338:669-74

2. van der Maas PJ, van Delden JJM, Pijnenborg L. Euthanasia and other medical decisions concerning the end of life. Health Policy 1992;22(1/2) 3. van der Wal G, Dillmann RJM. Euthanasia in the Netherlands. BMJ 1994;308:1346-9.

4. van der Wal G, van der Maas PJ, Bosma JM, et al. Evaluation of the notification procedure for physician-assisted death in the Netherlands. N Engl J Med 1996;335:1706-11.

5. Cochran WG. Sampling techniques. 2nd ed. New York: Wiley, 1963. 6. Pijnenborg L, van der Maas PJ, van Delden JJM, Looman CWN. Lifeterminating acts without explicit request of patient. Lancet 1993;341 1196-9

7. Emanuel EJ, Fairclough DL, Daniels ER, Clarridge BR. Euthanasia and physician-assisted suicide: attitudes and experiences of oncology patients, oncologists, and the public. Lancet 1996;347:1805-10.

8. Ward BJ, Tate PA. Attitudes among NHS doctors to requests for euthanasia. BMJ 1994;308:1332-4.

9. Stevens CA, Hassan R. Management of death, dying and euthanasia: at titudes and practices of medical practitioners in South Australia. J Med Ethics 1994;20:41-6.

10. Folker AP, Holtug N, Jensen AB, Kappel K, Nielsen JK, Norup M. Experiences and attitudes towards end-of-life decisions amongst Danish physicians. Bioethics 1996;10:233-49.

11. Lee MA, Nelson HD, Tilden VP, Ganzini L, Schmidt TA, Tolle SW. Legalizing assisted suicide - views of physicians in Oregon. N Engl J Med 1996;334:310-5.

12. Black AL, Wallace JI, Starks HE, Pearlman RA. Physician-assisted suicide and euthanasia in Washington State: patient requests and physician responses. JAMA 1996;275:919-25.

13. Position paper on euthanasia. Utrecht, the Netherlands: Royal Dutch Medical Association, 1995.

14. van der Wal G, van der Maas PJ. Euthanasie en andere medische beslissingen rond het levenseinde. The Hague, the Netherlands: Staatsuitgeverij, 1996 


\title{
EVALUATION OF THE NOTIFICATION PROCEDURE FOR PHYSICIAN-ASSISTED DEATH IN THE NETHERLANDS
}

\author{
Gerrit van der Wal, M.D., Ph.D., Paul J. van der Maas, M.D., Ph.D., Jacoueline M. Bosma, M.D., LL.M., \\ Bregje D. Onwuteaka-Philipsen, M.Sc., Dick L. Willems, M.D., Ph.D., Ilinka Haverkate, M.Sc., \\ ANd Piet J. Kostense, Ph.D.
}

\begin{abstract}
Background In the Netherlands, a notification procedure for physician-assisted death has been in use since 1991. It requires doctors to report each case to the coroner, who in turn notifies the public prosecutor. Ultimately, the Assembly of Prosecutors General decides whether to prosecute. Although physicianassisted death remains technically illegal, doctors are extremely unlikely to be prosecuted if they comply with the requirements for accepted practice. In 1995, the ministers of health and justice commissioned an evaluation to determine the adequacy of the notification procedure.
\end{abstract}

Methods A random sample of 405 physicians were interviewed. We also interviewed 147 physicians who had reported cases of physician-assisted death and 116 coroners, and we reviewed 353 judicial files of reported cases. In addition, we interviewed 48 public prosecutors and reviewed the minutes of the Assembly of Prosecutors General for 1991 to 1995 and all published court decisions from 1981 through 1995.

Results In 1995, about 41 percent of all cases of euthanasia and physician-assisted suicide were reported. There were no major differences between reported and unreported cases in terms of the patients' characteristics, clinical conditions, or reasons for the action. Most patients had cancer and were described as suffering "unbearably" and "hopelessly." Of the 6324 cases reported during the period from 1991 through 1995, only 13 involved prosecution of the physician. The majority of respondents in the groups interviewed thought that all cases of physician-assisted death should be reviewed, although most doctors thought the review should be performed by other doctors, and there was substantial concern about the burden associated with the reporting procedure.

Conclusions Substantial progress in the oversight of physician-assisted death has been achieved in the Netherlands. The reporting procedure could be more streamlined and less threatening. ( $N$ Engl J Med 1996;335:1706-11.)

(C)1996, Massachusetts Medical Society.

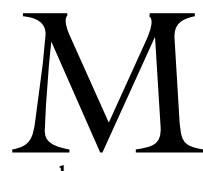

EDICAL decisions are normally made in the privacy of the doctor-patient relationship. ${ }^{1}$ Decisions that involve physician-assisted death, however, require at least regulatory oversight because of the risk of abusing vulnerable patients. ${ }^{2}$ A primary concern with regard to physician-assisted death is whether it is possible to establish adequate safeguards against such abuses. ${ }^{3}$

In the Netherlands, physician-assisted death is still subject to criminal law. Yet euthanasia and physicianassisted suicide have been practiced with increasing openness since the 1970s and are supported by public opinion, the majority of physicians, and case law. ${ }^{4-6}$ Requirements for accepted practice have been formulated by courts and the medical profession, and in general, a physician will not be prosecuted if he or she acts in accordance with these requirements. ${ }^{7}$ The requirements are as follows: the patient must consider his or her suffering unbearable and hopeless; the wish to die must be well considered and persistent; the request must be voluntary; the physician must consult at least one other physician; and the physician may not ascribe the death to natural causes and is obliged to keep records. In addition, most hospitals and nursing homes have written policies governing euthanasia and assisted suicide. ${ }^{8}$

To establish a mechanism for public oversight, a notification procedure was agreed on in 1990 by the minister of justice and the Royal Dutch Medical Association. This procedure has been in use since 1991 and was enacted legally by the Dutch legislature in June 1994.

The purposes of the notification procedure are to encourage physicians to disclose cases in which they have assisted in a patient's death, to promote adherence to the requirements for accepted practice, and to ensure that the reporting of physician-assisted death is uniform throughout the country. According to the procedure, a physician who has assisted in a patient's death does not issue a certificate of natural death but instead informs the coroner that it was a physician-assisted death. The physician is expected to use an official checklist with questions about the medical history, the request of the patient, the drugs used to cause death, and the report of the other physician consulted. The coroner then conducts a

From the Institute for Research in Extramural Medicine (G.W., J.M.B. B.D.O.-P., D.L.W., I.H., P.J.K.), the Department of General Practice, Nursing Home, and Social Medicine (G.W.), and the Department of Epidemiology and Biostatistics (P.J.K.), Vrije Universiteit Amsterdam, Amsterdam; and the Department of Public Health, Erasmus University, Rotterdam (P.J.M.) - both in the Netherlands. Address reprint requests to Dr. van der Wal at Vrije Universiteit, EMGO Institute, Van der Boechorststraat 7, 1081 BT Amsterdam, the Netherlands. 
postmortem examination, collects the relevant data, informs the public prosecutor of the death, and submits all the relevant documents. The public prosecutor decides whether to permit burial or cremation, examines the record, and presents a judgment to the prosecutor general. The latter, usually assisted by an advocate general, presents the case, together with his or her own opinion, to the Assembly of Prosecutors General, which has five members. The assembly provisionally decides whether or not to prosecute. The final decision with regard to prosecution is made by the minister of justice.

In 1995 the ministers of health and justice commissioned an evaluation of the notification procedure to determine whether it is serving the purposes for which it was established.

\section{METHODS}

We interviewed a stratified random sample of 405 physicians. This sample was representative of all Dutch physicians. The study methods are described elsewhere in this issue.?

We also interviewed a random sample of 175 physicians, stratified according to judicial multidistrict area and type of practice (general practice, medical specialty, nursing home practice), selected from the 741 physicians reporting cases of physician-assisted death (a total of 804) between August 1, 1994, and February 1, 1995. A total of 28 physicians were not interviewed: 6 could not be traced, 4 had already been included in the larger random sample, 1 was involved in a case that had not yet been closed, and 17 (10 percent) refused to participate in the study. In addition to background characteristics, the 147 physicians were asked about the reported cases of physician-assisted death, the most recent unreported case (if applicable), and their opinions on the notification and review procedures.

We interviewed 116 of the coroners involved in the cases reported by the 147 physicians. In the Netherlands, coroners can be private general practitioners or physicians working for public health departments. To obtain a sample that would be representative of both groups, the coroners were selected in such a way that all public health departments involved were represented, and no more than two coroners per public health department were interviewed. None of the coroners refused to participate. There were 34 private general practitioners and 82 physicians working for public health departments.

The interviews with physicians and coroners were conducted by 21 experienced physicians and 4 experienced coroners, respectively, all of whom received training in interviewing. The interviews were based on an extensive, structured questionnaire and lasted for $2 \frac{1}{2}$ hours, on average.

To extrapolate the results of the interviews with the 147 physicians to all physicians who reported cases between August 1, 1994, and February 1, 1995, we used weights that accounted for the stratification of the sample. Similarly, to extrapolate the results of interviews with the 116 coroners to all coroners who were involved in the reported cases, we used weights that took into account the selection procedure.

Of the 804 cases of physician-assisted death reported between August 1, 1994, and February 1, 1995, 363 were randomly selected from the public prosecutors' files, stratified according to judicial district. Ten files could not be found in the public prosecutors' offices. Information about the characteristics of the cases was obtained from the other 353 files.

The overall numbers of reported cases per year were derived from the registers of the public prosecutors and from a data base set up by the ministry of justice for this study.

Detailed interviews were also conducted with 48 officials: 39 public prosecutors $(2$ from each judicial district $[3$ from three large districts]) and the 4 advocates general and 5 prosecutors general involved in the five judicial multidistrict areas.

The confidential minutes of the Assembly of Prosecutors General for sessions involving reported cases of physician-assisted death were made available to us for the purpose of this study. All minutes of meetings from 1991 through 1995 were independently analyzed by two investigators. All published court decisions concerning cases of physician-assisted death from 1981 through 1995 were also analyzed.

The 95 percent confidence intervals for differences between proportions were calculated with McNemar's test, which takes into account the fact that these are matched data. Calculations were performed with the Confidence Interval Analysis computer program. ${ }^{10}$

\section{RESULTS}

\section{Number of Reported Cases}

The number of reported cases of physician-assisted death gradually increased to 486 in 1990, increased steeply to 1201 in 1992 , and then gradually leveled off to 1466 in 1995 (Table 1). The estimated numbers of cases of euthanasia and physician-assisted suicide were 2700 in 1990 and 3600 in 1995\%; the notification rate thus increased from about 18 percent to 41 percent during that period. Cases of physicianassisted death without the patient's explicit request were rarely reported: two cases were reported in 1990, and three in 1995. (In the Netherlands we do not use the term "euthanasia" for these cases.)

\section{Physicians' Reasons for Reporting or Not Reporting Cases}

The most important reasons cited for reporting cases of physician-assisted death were as follows: the physician reports all cases (75 percent), reporting is obligatory (17 percent), it is the official policy of the physician's institution (13 percent), and it gives an account to society (13 percent). (Some physicians gave more than one reason.) Asked about their experiences with the notification procedure, some physicians had negative responses (it is time-consuming [37 percent], burdensome [30 percent], incriminating [11 percent], or a breach of privacy [5 percent]); some were neutral (30 percent); and others said they felt supported (19 percent), had positive views (13 percent), or felt relieved by the procedure $(7$ percent). (Some physicians gave more than one response.)

In the interviews with the random sample of 405 physicians, 49 said they had not reported the most recent case of assisting with a patient's death at the explicit request of the patient. They gave the following reasons for not doing so: a wish to avoid the fuss of a judicial inquiry ( 25 physicians), a wish to protect the patient's relatives from a judicial inquiry (12), a request from the patient's relatives to be protected from a judicial inquiry (10), fear of prosecution (10), failure to fulfill the requirements for accepted practice $(8)$, and the belief that assistance with death should be a private matter between doctor and patient (6). Of these 49 physicians, 7 said 
Table 1. Physician-Assisted Deaths Reported to Public Prosecutors, Discussed in the Assembly of Prosecutors General, and Subjected to Inquests, Prosecutions, and Published Court Decisions, 1981-1995.*

\begin{tabular}{|c|c|c|c|c|c|}
\hline YeAR & $\begin{array}{l}\text { No. of } \\
\text { REPORTED } \\
\text { CASES }\end{array}$ & $\begin{array}{c}\text { No. OF CASES } \\
\text { Discussed IN } \\
\text { AsSEMBLy }\end{array}$ & $\begin{array}{l}\text { No. OF } \\
\text { INOUESTS } \\
\text { FoLLOWED BY } \\
\text { DISMISSAL }\end{array}$ & $\begin{array}{l}\text { No. of } \\
\text { ProseCU- } \\
\text { TIONS }\end{array}$ & $\begin{array}{l}\text { Published } \\
\text { Court } \\
\text { Decisiont }\end{array}$ \\
\hline $\begin{array}{r}1981- \\
1985\end{array}$ & 71 & NA & 1 & 8 & $\mathrm{I}$ acquittal \\
\hline 1986 & 84 & NA & 1 & 2 & $\begin{array}{l}2 \text { acquittals, } 1 \\
\text { suspended } \\
\text { sentence }\end{array}$ \\
\hline 1987 & 126 & NA & 1 & 3 & $\begin{array}{l}1 \text { acquittal with } \\
\text { a fine, } 1 \text { dis- } \\
\text { charge }\end{array}$ \\
\hline 1988 & 184 & NA & 1 & 2 & $\begin{array}{l}2 \text { suspended } \\
\text { sentences } \\
\text { (1 with a fine) }\end{array}$ \\
\hline 1989 & 338 & NA & 2 & 1 & $\begin{array}{l}1 \text { acquittal with } \\
\text { a fine }\end{array}$ \\
\hline 1990 & 486 & NA & 0 & 0 & 0 \\
\hline 1991 & 866 & 14 & 0 & 1 & I discharge \\
\hline 1992 & 1201 & 17 & 2 & 2 & 0 \\
\hline 1993 & 1304 & 26 & 11 & 4 & 2 acquittals \\
\hline 1994 & 1487 & $27 \ddagger$ & 6 & 5 & $\begin{array}{l}1 \text { acquittal, } 2 \\
\text { guilty without } \\
\text { punishment }\end{array}$ \\
\hline 1995 & 1466 & $36 \$$ & 3 & 1 & $\begin{array}{l}1 \text { acquittal, } \\
3 \text { suspended } \\
\text { sentences (1 } \\
\text { with a fine), 1 } \\
\text { guilty without } \\
\text { punishment }\end{array}$ \\
\hline
\end{tabular}

*NA denotes data not available. Before 1990 reported cases are listed according to the date of discussion in the Assembly of Prosecutors General; for 1990 and after, reported cases are listed according to the date of death and the respective notification. Between these dates there can be months of delay.

†Between the year of prosecution and the year of the published final court decision, there can be an interval of one or more years.

In three other cases the inquiry has not yet been completed.

\$In two cases the physicians were discharged of liability for conviction by payment of a fixed fine, because they had reported cases of euthanasia as natural deaths. In four other cases the inquiry has not yet been completed.

they would never report a case of physician-assisted death. Of the 70 respondents who had not reported the most recent case of assisting with a patient's death in the absence of an explicit request from the patient, 37 said that in their opinion it had been a natural death, and 36 said they would never report such a case.

\section{Characteristics of Reported and Unreported Cases}

Of the 147 respondents who had reported cases of assisted death, 84 said they had decided not to report at least one other case. (After the sample had been weighted, these respondents corresponded to an estimated 52 percent of all physicians who reported a case of physician-assisted death.) These 84 physicians were also asked about the most recent un- reported case. Only 1 of the reported cases had involved assistance in ending life without an explicit request from the patient, whereas 16 of the 84 most recent unreported cases had involved assistance without the patient's explicit request.

Features of the other 68 reported and unreported cases of euthanasia and physician-assisted suicide are shown in Table 2.

There were no major differences between reported and unreported cases in terms of the patients' characteristics or the basis for the decision to provide assistance (i.e., whether there was an explicit request and unbearable and hopeless suffering). However, the procedural requirements were met less often in the unreported cases: a written request (44 percent in the unreported cases vs. 73 percent in the reported cases), consultation with another physician (11 percent vs. 94 percent), and a written report (57 percent vs. 97 percent). A comparison of the most recent reported and unreported cases in the larger random sample of physicians had similar results. A comparison of the most recent (reported and unreported) cases in 1990 and 1995 showed no differences in the percentage of cases in which the substantive requirements for accepted practice had been met. The results differed, however, with respect to procedural requirements. The decision had not been discussed with a colleague in 11 percent of the cases in 1995, as compared with 16 percent in 1990, and a written report was available in 81 percent of the cases in 1995, as compared with 60 percent in 1990. As shown in Table 1, the number of reported cases also showed a marked increase.

\section{Notification and Conclusion of Cases}

Before 1990, 60 percent of all reported cases of physician-assisted deaths were reported to a coroner, 42 percent to a public prosecutor, and 42 percent to the police. After 1990, 98 percent of reported cases were reported to a coroner, 7 percent to a public prosecutor, and none to the police. In 56 percent of the 353 judicial files studied, the physician had used the official checklist, which is part of the notification procedure, to present the relevant information.

The time between notification by the physician and notice of the conclusion of the judicial procedure was, on average, 103 days for cases that were dismissed without further examination. This period varied greatly by district. Cases that were the subject of an inquest or were brought to court took much longer, sometimes several years.

\section{Examination by Public Prosecutors}

Of the 6324 cases reported from 1991 through 1995, 120 were discussed by the Assembly of Prosecutors General. Inquests were conducted in 21 cases (involving 22 physicians) and dismissed; 13 physicians were prosecuted. The percentage of cases that result- 
TABle 2. Characteristics of Reported ANd UnReported Cases of Euthanasia and Assisted Suicide.

\begin{tabular}{|c|c|c|c|}
\hline Characteristic & $\begin{array}{l}\text { REPORTED } \\
\text { CASES } \\
(\mathrm{N}=68)\end{array}$ & $\begin{array}{l}\text { UNREPORTED } \\
\text { CASES } \\
(\mathrm{N}=68)\end{array}$ & $\begin{array}{l}\text { DIFFERENCE BETWEEN } \\
\text { REPORTED AND } \\
\text { UNREPORTED CASES } \\
(95 \% \mathrm{CI})^{*}\end{array}$ \\
\hline \multicolumn{4}{|c|}{$\%$ of cases } \\
\hline \multicolumn{4}{|l|}{ Patients } \\
\hline \multicolumn{4}{|l|}{ Sex } \\
\hline Male & 52 & 62 & $-10.6(-25.8$ to 4.6$)$ \\
\hline Female & 49 & 38 & $10.6(-4.6$ to 25.8$)$ \\
\hline \multicolumn{4}{|l|}{ Age $(\mathrm{yr})$} \\
\hline $0-49$ & 26 & 11 & $15.2(1.3$ to 23.8$)$ \\
\hline $50-64$ & 33 & 17 & $16.7(2.4$ to 31$)$ \\
\hline $65-79$ & 27 & 50 & $-22.7(-38.9$ to -6.6$)$ \\
\hline$\geqslant 80$ & 14 & 23 & $-9.1(-22.2$ to 4$)$ \\
\hline \multicolumn{4}{|l|}{ Diagnosis } \\
\hline Malignant neoplasm & 65 & 79 & $-13.6(-23.5$ to 0.7$)$ \\
\hline $\begin{array}{l}\text { Disease of the circu- } \\
\text { latory system }\end{array}$ & 8 & 8 & $0.0(-9.5$ to 9.5$)$ \\
\hline $\begin{array}{l}\text { Disease of the ner- } \\
\text { vous system }\end{array}$ & 12 & 3 & $9.1(-0.6$ to 12$)$ \\
\hline $\begin{array}{l}\text { Disease of the res- } \\
\text { piratory system }\end{array}$ & 5 & 5 & $0.0(-5.2$ to 5.2$)$ \\
\hline Other diseases & 11 & 6 & $4.6(-5.5$ to 11.6$)$ \\
\hline \multicolumn{4}{|l|}{ Estimated survival† } \\
\hline$>6 \mathrm{mo}$ & 20 & 8 & $11.5(-1.6$ to 19.2$)$ \\
\hline 1 to $6 \mathrm{mo}$ & 13 & 25 & $-11.7(-23.7$ to 4.2$)$ \\
\hline$>\mathrm{l}$ wk to $<\mathrm{l} \mathrm{mo}$ & 40 & 33 & $6.7(-11.7$ to 25.1$)$ \\
\hline $1 \mathrm{wk}$ at most & 20 & 25 & $-5.0(-17.9$ to 9.7$)$ \\
\hline$<24 \mathrm{hr}$ & 7 & 8 & $-1.7(-10.9$ to 8.6$)$ \\
\hline \multicolumn{4}{|l|}{$\begin{array}{l}\text { Requirements for pru- } \\
\text { dent practice }\end{array}$} \\
\hline \multicolumn{4}{|l|}{ Patient's request } \\
\hline Highly explicit & 100 & 92 & $7.6(-0.3$ to 7.6$)$ \\
\hline Rather explicit & 0 & 8 & $-7.6(-7.6$ to 0.3$)$ \\
\hline Written will present & 73 & 44 & $28.6(11.9$ to 45.3$)$ \\
\hline \multicolumn{4}{|l|}{ Unbearable suffering } \\
\hline Utterly & 64 & 64 & $0.0(-15.6$ to 15.6$)$ \\
\hline To a high degree & 23 & 23 & $0.0(-14.4$ to 14.4$)$ \\
\hline To a lesser degree & 13 & 13 & $0.0(-8.6$ to 8.6$)$ \\
\hline \multicolumn{4}{|l|}{ Hopeless suffering } \\
\hline Utterly & 86 & 88 & $-1.6(-14.4$ to 11.8$)$ \\
\hline To a high degree & 11 & 11 & $0.0(-11.8$ to 11.8$)$ \\
\hline To a lesser degree & 3 & 2 & $1.6(-3.8$ to 4.6$)$ \\
\hline $\begin{array}{l}\text { Alternative treatments } \\
\text { available }\end{array}$ & 26 & 24 & $1.5(-12.7$ to 15.8$)$ \\
\hline Consultation & 94 & 11 & $83.1(72.1$ to 83.1$)$ \\
\hline \multicolumn{4}{|l|}{$\begin{array}{l}\text { Written report on de- } \\
\text { cision making }\end{array}$} \\
\hline Yes, separate report $\$$ & 36 & 0 & $35.8(25.6$ to 35.8$)$ \\
\hline $\begin{array}{l}\text { Yes, notes in the } \\
\text { medical record } \$\end{array}$ & 84 & 57 & $26.9(11.7$ to 35.4$)$ \\
\hline No & 3 & 43 & $-40.3(-43.2$ to -27.9$)$ \\
\hline \multicolumn{4}{|l|}{ Other } \\
\hline $\begin{array}{l}\text { Discussion with col- } \\
\text { leagues }\end{array}$ & 100 & 58 & $42.4(32$ to 42.4$)$ \\
\hline $\begin{array}{l}\text { Contact with patient's } \\
\text { relatives }\end{array}$ & 99 & 92 & $6.1(-2.6$ to 9$)$ \\
\hline $\begin{array}{l}\text { No technical problems } \\
\text { with administra- } \\
\text { tion of drugs }\end{array}$ & 88 & 91 & $-3.1(-11.6$ to 7.3$)$ \\
\hline
\end{tabular}

${ }^{*} \mathrm{CI}$ denotes confidence interval. The exact confidence intervals are shown; the differences have been rounded and may therefore appear to lie outside the confidence intervals.

†Estimated survival was defined as the number of remaining months, weeks, or hours a patient was expected to survive in the absence of any intervention.

$\ddagger$ More than one answer could be given

\$Both were available for some patients. ed in prosecution was much smaller than that in the previous decade (Table 1). The most important reasons for further discussion in the assembly were as follows: the patient was not yet in the terminal phase of disease (in 38 percent of the cases), the request was absent or unclear ( 25 percent), the consultation was absent or inadequate ( 24 percent), there was doubt that the patient's suffering had been unbearable and hopeless (23 percent), and the physician's performance was inadequate (13 percent) (Table 3 ). Prosecution was initiated in cases of flagrant violation of the requirements for accepted practice and, in some cases, to establish a test case to elicit jurisprudence. In the overall total of 20 published final court decisions regarding 18 cases of physician-assisted death, 9 physicians were acquitted, mostly because their actions were deemed medically necessary; 2 were discharged from further prosecution, 3 were found guilty but not punished, and 6 were given suspended sentences of one week to six months (Table 1).

\section{Opinions about Notification and Review Procedures}

The majority of the respondents in the different groups interviewed thought that every case of physician-assisted death should be reviewed; however, 35 percent of respondents in the large random sample of physicians did not. Of the physicians in this group who thought every case should be examined, 30 percent thought the decision should be reviewed only before the fact. In the other groups, this percentage was lower. The majority of respondents in the four groups thought that if cases were to be reviewed before the fact, the review should be performed by members of the medical profession. Most physicians thought the review should be carried out by an independent consultant. Only one public prosecutor considered it sufficient to review cases before the fact. In each group, a large proportion of respondents thought it necessary to review cases both before and after the fact. Opinions about who should review cases after the fact varied widely and often reflected the respondent's position. Thus, 51 percent of the public prosecutors thought they should have the responsibility for the review, and 63 percent of the coroners thought it should be their responsibility.

\section{DISCUSSION}

This study provides insight into the functioning of a legal notification procedure for physician-assisted death. The study had the following strengths: most of the respondents were willing to participate in the extensive interviews (refusal rate, 0 to 11 percent); we had complete access to all confidential documents; the study was supported by the Royal Dutch Medical Association, the chief inspector for health care, and the ministers of health and justice; and the data collected could not be used for legal prosecution.

Does the notification procedure encourage physi- 
Table 3. Most Important Reason for Discussing 120 Reported Cases in the Assembly of Prosecutors General, 1991-1995.

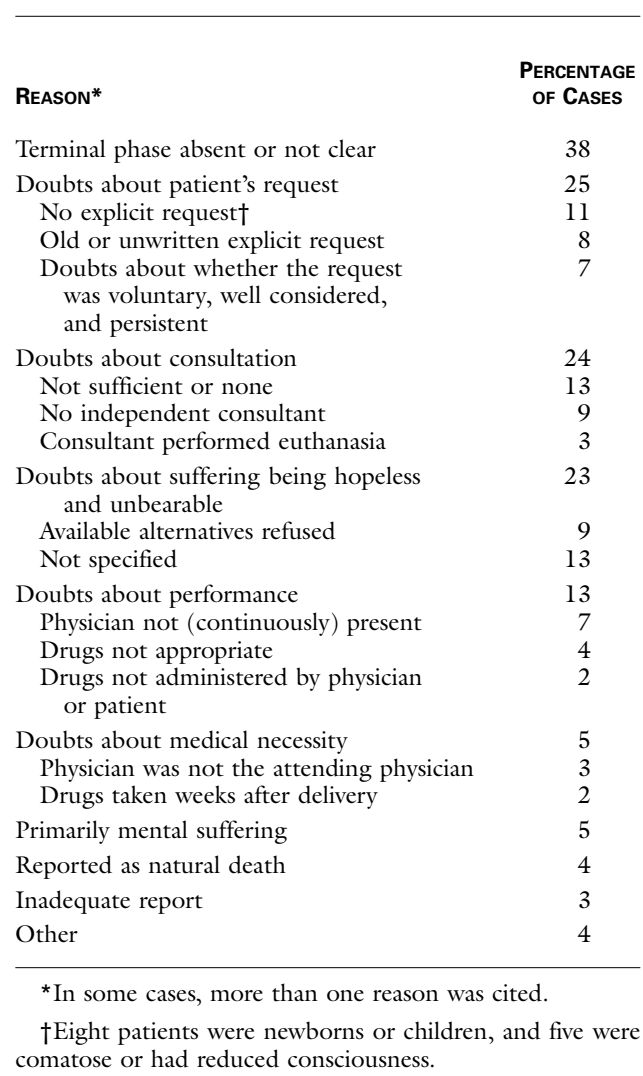

cians to disclose their practice of assisting with death? The rate of notification about cases of euthanasia and physician-assisted suicide rose from an estimated 18 percent in 1990 to about 41 percent in 1995. Notification about cases that did not involve the explicit request of the patient remained very low, which is not surprising in view of the statement by the previous minister of justice that reporting such acts would always be prosecuted.

Does the notification procedure promote adherence to the requirements for accepted practice? A comparison of the 1990 and 1995 data shows that procedural requirements are met more often nowadays. Procedural requirements, of course, are also met more often in reported cases than in unreported cases. The substantive requirements for accepted practice were met in the large majority of cases, reported and unreported, and have been since 1990 .

Does the notification procedure ensure that the reporting of physician-assisted death is dealt with uniformly throughout the country? Uniformity in reporting has been obtained to a large extent at the beginning and at the end of the notification procedure: almost all reported cases have been reported to a coroner, and all reported cases have finally been presented in the Assembly of Prosecutors General, which promotes uniformity in the prosecution policy in all districts. Other aspects of the notification procedure still vary greatly. The checklist that is part of the procedure is used by only about half the physicians, and the time between notification and informing the physician whether the case has been dismissed varies widely among districts.

The results of our study show that the notification procedure has improved public oversight in this area. At the same time, our data show that there is still a large difference between the number of cases reported and the number that should be reported. This is particularly true of cases in which there was no explicit request from the patient.

Our study shows that a large majority of Dutch physicians are willing to have cases of physicianassisted death reviewed. The very high rates of participation in studies such as ours reflect the support of the medical profession for some form of public oversight in this area. Most physicians, however, seem to prefer that cases not be examined by public prosecutors. Perhaps the notification procedure should be modified in that respect. If physicians were better informed about the percentage of cases that are prosecuted and the reasons for prosecution, their fear of prosecution might be largely eliminated, and their willingness to report cases increased. The review of reported cases could also be improved by reducing the burden associated with the procedure and the required paperwork and by completing the review more rapidly. Explicit formulation of the nonprosecution policy by public prosecutors might also increase physicians' willingness to report cases. Furthermore, an explicit policy might enable cases to be settled at the district level, while maintaining uniformity throughout the country. If there is a further increase in the number of reported cases, that will become necessary in order to avoid congestion at the level of the Assembly of Prosecutors General.

The number of reported cases of physician-assisted death will probably continue to increase, but there will always be some cases in which not all the requirements are met, and these are the cases that are likely not to be reported. The most difficult situations will continue to involve terminally ill, suffering patients who are not able to express their wishes and have no advance directives. Physicians are likely to be more open to review if it is performed in a less threatening and more educational fashion, with more involvement from the medical profession.

We believe that cautious optimism is warranted. There seems to be only a small increase in the number of cases of euthanasia, there are indications that decision making has improved, the number of reported cases has greatly increased, and options for further improvement in public oversight have been identified. Nevertheless, there are limits to any sys- 
Table 4. Opinions about Notification and Review Procedures.

\begin{tabular}{|c|c|c|c|c|}
\hline \multirow[t]{2}{*}{ OPINION } & $\begin{array}{c}\text { Random Sample } \\
\text { OF Physicians }\end{array}$ & $\begin{array}{l}\text { Physicians Reporting } \\
\text { Assisted Deaths }\end{array}$ & Coroners & $\begin{array}{c}\text { Public } \\
\text { Prosecutors }\end{array}$ \\
\hline & \multicolumn{4}{|c|}{ weighted percentage } \\
\hline \multicolumn{5}{|c|}{ Every case of physician-assisted death should be examined } \\
\hline No. of respondents & 405 & 147 & 116 & 48 \\
\hline Yes & 65 & 88 & 93 & 92 \\
\hline No & 35 & 12 & 7 & 8 \\
\hline \multicolumn{5}{|l|}{ Appropriate time for the review* } \\
\hline No. of respondents & 358 & 138 & 112 & 48 \\
\hline Before assisted death & 30 & 16 & 17 & 2 \\
\hline After assisted death & 28 & 24 & 26 & 46 \\
\hline Both & 42 & 60 & 57 & 52 \\
\hline \multicolumn{5}{|l|}{ Appropriate reviewer and time $\dagger$} \\
\hline No. of respondents before/after & $266 / 250$ & $105 / 115$ & $84 / 94$ & $26 / 47$ \\
\hline \multicolumn{5}{|l|}{ Medical professional } \\
\hline Before & 86 & 81 & 71 & 66 \\
\hline After & 42 & 31 & 22 & 13 \\
\hline \multicolumn{5}{|c|}{ Committee not restricted to medical profession } \\
\hline Before & 22 & 16 & 42 & 58 \\
\hline After & 34 & 30 & 36 & 36 \\
\hline \multicolumn{5}{|l|}{ Inspectorate for health caref } \\
\hline \multicolumn{5}{|l|}{ Before } \\
\hline After & 18 & 14 & 16 & 23 \\
\hline \multicolumn{5}{|l|}{ Coroner $\ddagger$} \\
\hline \multicolumn{5}{|l|}{ Before } \\
\hline After & 25 & 30 & 63 & 19 \\
\hline \multicolumn{5}{|l|}{ Public prosecutor $\ddagger$} \\
\hline \multicolumn{5}{|l|}{ Before } \\
\hline After & 20 & 18 & 37 & 51 \\
\hline \multicolumn{5}{|l|}{ Others } \\
\hline Before & 15 & 10 & 28 & 8 \\
\hline After & 16 & 15 & 10 & 19 \\
\hline \multicolumn{5}{|l|}{ Cases that should be examined afterward } \\
\hline No. of respondents & 243 & 110 & 92 & 47 \\
\hline All cases & 66 & 81 & 84 & 85 \\
\hline Randomly selected cases & 17 & 4 & 7 & 0 \\
\hline Doubtful cases, selected beforehand & 12 & 9 & 6 & 6 \\
\hline Other & 6 & 3 & 3 & 9 \\
\hline
\end{tabular}

*Eighty physicians from the larger random sample, 14 physicians from the reporting-physicians sample, 5 coroners, and 4 public prosecutors who answered "no" to the first question qualified their answer by saying, "No, not always." These respondents also answered the other questions reported in this table.

†Categories of answers were offered to respondents in writing. More than one answer could be given to this question.

‡These categories were not offered as answers to the question "Who should examine beforehand?"

tem of oversight. Some decisions will continue to be considered by both doctor and patient to be private, and some tension will remain between the public and the private domain, as in other aspects of medicine. Close monitoring of the practice of physicianassisted death is both necessary and possible.

Supported by a grant from the Dutch Ministry of Justice and Ministry of Health, Welfare, and Sports.

We are indebted to Johanna H. Groenewoud, M.D., Agnes van der Heide, M.D., Ph.D., and Martien T. Muller, Ph.D., for their contributions to the study and the manuscript; to Rita Verdurmen for her contribution to the study; to David Schweigman, M.A., and Etienne M.H.H. Wolfs for their contribution to the judicial-file study; to the interviewers for interviewing the physicians and the public prosecutors; to the members of the steering committee for their continuous support during the study; to the physicians and public prosecutors who provided the information for the study; and to the Royal Dutch Medical Association and the chief inspector for bealth care for their support of the study.

\section{REFERENCES}

1. Annas GJ, Glantz LH, Mariner WK. The right of privacy protects the doctor-patient relationship. JAMA 1990;263:858-61.

2. Miller FG, Quill TE, Brody H, Fletcher JC, Gostin LO, Meier DE. Regulating physician-assisted death. N Engl J Med 1994;331:119-23. 3. Annas GJ. Death by prescription - the Oregon Initiative. N Engl J Med 1994;331:1240-3.

4. van der Maas PJ, van Delden JJM, Pijnenborg L, Looman CWN. Euthanasia and other medical decisions concerning the end of life. Lancet 1991;338:669-74

5. van der Maas PJ, van Delden JJM, Pijnenborg L. Euthanasia and other medical decisions concerning the end of life. Health Policy 1992;22(1/2) 6. van der Maas PJ, Pijnenborg L, van Delden JJ. Changes in Dutch opinions on active euthanasia, 1966 through 1991. JAMA 1995;273:1411-4.

7. van der Wal G, Dillmann RJM. Euthanasia in the Netherlands. BMJ 1994;308:1346-9.

8. Haverkate I, van der Wal G. Policies on medical decisions concerning the end of life in Dutch health care institutions. JAMA 1996;275:435-9. 9. van der Maas PJ, van der Wal G, Haverkate I, et al. Euthanasia, physician-assisted suicide, and other medical practices involving the end of life in the Netherlands, 1990-1995. N Engl J Med 1996;335:1699-705.

10. Gardner MJ, Altman DG. Calculating confidence intervals for proportions and their differences. In: Gardner MJ, Altman DJ, eds. Statistics with confidence - confidence intervals and statistical guidelines. London: BMJ, 1989:28-33. 